$R M x A C, \mathbf{5 2}, 25-26(2020)$

(c) 2020: Instituto de Astronomía, Universidad Nacional Autónoma de México

https://doi.org/10.22201/ia.14052059p.2020.52.10

\title{
BRIEF HISTORY OF THE NATIONAL ASTRONOMICAL OBSERVATORY
}

\author{
Rodolfo Zalles ${ }^{1,2}$ \\ RESUMEN
}

En el presente trabajo se presenta una breve reseña sobre la historia del Observatorio Astronómico Nacional, sobre la cooperación de la URSS en la creación de este observatorio, sobre las observaciones astronómicas en el campo de la astrometriá y la astrofísica, y sobre la nueva etapa de colaboración con Rusia en el campo de observación de basura espacial. Tambien se presenta la cooperación del Japón que permitió ampliar las actividades en lo que se refiere a la difusión de la astronomía con la donación de un planetario GOTO.

\section{ABSTRACT}

In the present work, we present a brief review about the history of the National Astronomical Observatory, about the cooperation of the USSR in the creation of this observatory, about the astronomical observations in the astrometry and astrophysics areas and about the new stage of cooperation with Russia in the area of observations of space debris. The cooperation of Japan, which allowed to extend the activities in respect of astronomy diffusion with the donation of a GOTO planetarium is also presented.

Key Words: history and philosophy of astronomy

\section{INTRODUCTION}

In 1982 at the initiative of the Principal Astronomical Observatory of the Academy of the USSR Pulkovo an expedition of specialists of Russia arrived to Bolivia with the purpose of locating an appropriate place to carry out astronomical observations in the southern hemisphere. After visiting different places, they decided on the location of Santa Ana in the province of Cercado in the Department of Tarija, $15 \mathrm{~km}$ south east of the city of Tarija.

In 1983, they started the astrometric observations with the first telescope installed, an Astrograph expedition (Polozhentsev 1991), later they installed a Zeiss 600 telescope for the astrophysical observations and telescopes for the observation of space debris.

In 2009 the activities of the Planetarium GS donated by Japan began. Since then it has continuously played host to school children, students, domestic and foreign tourists, and general public.

\section{MAIN PHASES OF THE OBSERVATORY}

1982 - Signature of the agreement and recognition of the area.

1983 - Installation of the Astrograph and the beginning of astrometry observations.

1984 - Official opening of the Observatory.

\footnotetext{
${ }^{1}$ Universidad Autónoma Juan Misael Saracho de Tarija, Bolivia (rozalles@hotmail.com).

${ }^{2}$ Observatorio Astronómico Nacional, Tarija, Bolivia.
}

1986 - Installation of the Zeiss-600 telescope, and beginning of astrophysical observations.

1987 - Installation of the AZT-7 telescope .

1988 - Installation of the AFU 75 camera and the laser intercoms for artificial satellites observations.

1989 - Transportation of the second Zeiss-600 telescope.

1990 - The cooperation was interrupted due to Perestroika.

1993 - Enactment of the Republic Law, which declares the observatory to be a national institution.

2005 - Experimental observations of space debris with the Astrograph begin.

2005 - Japan formalizes the donation of a planetarium to the observatory.

2006 - Completion of the planetarium infrastructure.

2006 - The planetarium equipment arrives to Tarija.

2008 - Installation and commissioning of the GOTO GS planetarium.

2009 - Installation of the Sigma Ori 25 telescope for the ISON program.

2010 - Modernization of the second telescope Zeiss 600-2AA telescope.

2016 - Beginning of observations, with the telescope Zeiss 600-2 AA for the ISON program.

\section{ASTROMETRY}

It is important to note the following activities of the astrometric observations performed: 
A catalogue of 3666 southern hemisphere bright stars, up to mag 6.05, was constructed from 7262 photographic plates that were obtained.

FOCAT-S, 200000 stars up to mag 11 were observed (Bystrov 1994).

Coordinates of Halley's Comet, SOPROG program, IHW, were obtained from 113 photographic plates.

Exact coordinates of the SN 1987A, were obtained from 11 plates.

EKAT, Catalogue Equatorial zone of observation $-20^{\circ}$ up to $+10^{\circ}$ zone of declination, from approximately 1000000 stars up to mag 12 .

Catalogs for the space soviet missions, VEHA 1, 2 and Phobos.

\section{ASTROPHYSICS}

These observations were carried out with the Zeiss-600 and AZT-7 telescopes.

With this equipment we obtained a series of photometric and polarimetric observations of Halley's comet, in the framework of the International Halley Watch.

We actively participated in the international agenda for the study of the asteroid Vesta in 1986, and from these observations confiirmed the short rotation period of the asteroid.

We obtained multicolor photometric observations of the 1987 Large Magellanic Cloud supernova, also polarimetric and photometric observations of variable stars in the Orion constellation, of a satellite of Mars, Phobos and Deimos, of stellar systems binaries, and carried out studies on the spectral energy distribution from a number of spectra of selected stars in the southern hemisphere.

\section{SPACE DEBRIS}

Space debris observations were initiated in the framework of cooperation with the Institute of Applied Mathematics of the Russian Academy of Sciences. In 2007 they carried out experimental observations with the astrograph. At the end of 2009 the special telescope for this type of observations the SIGMA Ori 25 was installed; later it was joined by the Zeiss 600 AA telescope. From regular observations with these telescopes new fragments of space debris in geostationary orbit were discovered that had not been catalogued; since then we participate in the international network ISON (International Scientific Optical Network)(Molotov 2008).

\section{PLANETARIUM}

The Planetarium project arises from the need to create educational spaces. The main mission of the project is to return to the visitor the interrelationship lost with the cosmos, and strengthen it, through the dissemination of astronomical knowledge in all its aspects, descriptive, historical, physical, research and exploration, in a way that is accessible to the public.

Efforts made by the National Astronomical Observatory directorate before the Government of Japan, have succeeded in obtaining a donation of the necessary equipment to operate the Planetarium.

Our Planetarium, aims to be an area of knowledge and outreach of astronomy and related sciences; generating opportunities for access to knowledge to the entire educational community and population in general. Since its implementation and opening to the public on January 2009, the GOTO GS Planetarium of the National Astronomical Observatory of Tarija, has received an exceptional amount of public eager to discover what it means to have an astronomical session in the planetarium.

\section{ASTRONOMY DISSEMINATION ACTIVITIES}

Since its inauguration, the Observatory maintains an interaction with students, tourists and general public; great importance is given to the dissemination of astronomy in all its aspects and levels.

The Observatory provides an interesting opportunity for all visitors to our facility for visual observations and with telescopes of the sky, planetarium performances, courses, workshops, conferences, photographic exhibits, etc. We seek to enhance the teaching and dissemination of astronomy to schoolchildren, students, and the general public in order to achieve a knowledge of our sky and the importance of looking at the stars, to allow the understanding of constellations, planets, stars, clusters and nebulas and in addition to promote astrotourism, or scientific tourism.

\section{REFERENCES}

Bystrov, N. F., Polojentsev, D. D., Potter, H. I., et al. 1994, BICDS, 44, 3

Molotov, I., Agapov, V., Titenko, V., et al. 2008, AdSpR, 41, 1022

Polozhentsev, D. D., Potter, H. I., Zelaya, J. A., \& Zalles, R. 1991, Ap\&SS, 177, 215 